THE PANORAM KODAK.

FVER since the year 1845 , when Friedrich v. Martens, a copper-plate engraver living in Paris, constructed a camera with a rotating lens and arrangements for a curved plate for taking panoramic views, this method of working has engaged the attention of photographers. Martens's apparatus was designed for Daguerreotype plates, but the convenience of flexible films for such w'ork must very soon have been appreciated, for in 1850 we find Fox Talbot taking the trouble to state that one of his sensitive papers was particularly well adapted for the purpose.

M. Garella, in 1857 , employed a flat plate moving tangentially to the required curved surface as the camera rotated, and so obviated the necessity for the curving of the sensitive surface. Messrs. J. R. Johnson and J. A. Harrison worked on similar lines when they produced their " pantascopic camera" in I862, and its subsequent improvements. These and several other inventors suffered from the disadvantage of having to use glass plates which, whether flat or curved, were awk ward to manipulate, and if curved were costly and especially troublesome. Still, very excellent work was done with these apparatuses.

Modern panoramic cameras date, practically speaking, from the commercial preparation of flexible or film-supported sensitive surfaces. Commandant Moessard, in 1893 , employed a curved film supported in a curved celluloid holder, while M. I. Damoizeau (189r), in his "cyclographe," and Colonel R. W. Stewart, R.E. (1893), in his "panoram," employed films in the most compact way possible, drawing the film from one roller to another as the camera rotates. Colonel Stewart's camera is very small for the size of picture that it takes, and will, if required, photograph the whole horizon at one operation. $\mathrm{He}$ constructed his apparatus for Eastman's films.

But all these cameras were, comparatively speaking, costly, heavy and complicated, being actuated by clockwork or the equivalent, and the later examples were designed to be applicable to photographic surveying. No one appears to have considered it possible to construct a panoramic camera that should be light and simple in construction, and so available for the ordinary tourist, until the enterprising firm of Kodak, Ltd., introduced their " panoram kodak." In this camera they have not only succeeded to this extent, but have provided what is commonly understood as a "kodak"-that is, a camera that may easily be held in the hand during the exposure. Its construction is very ingenious in its simplicity. During exposure, the only moving part is the lens, which swings on a vertical axis, and the only motive power is a spring. The spring acts on a lever, and as the arrangement is laterally symmetrical, the exposure can be started from the side that the lens happens to be pointing towards. There is no shutter as ordinarily understood, the lens revolves through a half circle, and at each end of its journey is accommodated in a little recess that prevents any light passing through it to the inside of the camera.

The sensitive surface is the roller film, which passes over guides that maintain it at the correct curvature. The picture produced is seven inches long and $2 \frac{1}{4}$ inches high, and the definition is good over its whole length, showing that the difficulty of the correct adjustment of the swinging lens has been quite satisfactorily overcome. As already stated, the apparatus is of the simplest kind. The lens works always at the same aperture. It has two rates of movement, the equivalent of two speeds of a shutter, effected simply by putting the full or a partial tension on the spring. But long exposures can be given by just repeating the ordinary exposure as often as necessary, the camera, of course, being firmly supported. We have seen some excellent views of dark wooded scenery taken in this way.

It may be worth while to remind those who think that they would appreciate the possibility of getting views including a wide horizontal angle, that the perspective of the pictures produced by all such apparatus as that referred to is cylindric, and, being different from the more usual plane perspective of flat plates, requires different precautions on the part of the photographer to avoid unpleasant results. The chief of these precautions is due to the fact that horizontal lines that lie either above or below the axis of the lens are curved towards the axis. The horizon itself is, of course, never curved on the photograph if the camera is level, and the panoram is provided with a spirit level as a guide for this purpose. Speaking practically, the one kind of view to avoid may be exemplified by a long building photographed from a point approximately opposite to its centre, No. I 628 , voL. 63$]$ facing it, say, from the other side of the street. It is impossible by any means to set a satisfactory representation of such an object from such a position, but the temptation to make the attempt is greater with a panoramic camera than with the more usual apparatus.

Now that a panoramic camera suitable for ordinary purposes has been shown to be possible, we hope that the construction adopted will be applied to the production of other sizes and perhaps other qualities of apparatus.

C. J.

\section{SOME RECENT ADVANCES IN BIOLOGICAL SCIENCE. 1}

A TIME-HONOURED distinction has been drawn between the so-called observational and the experimental sciences; and, pledged as we are to the former, we have to deal with those subjécts which, in the hands of the immortal Darwin, have during the last forty years revolutionised all departments of science not wholly mathematical, for be it remembered that the formulation of the periodic law in chemistry is but that of an evolutionary hypothesis. So reactionary has been this influence upon thought and mental conduct, that it has rendered it impossible for us to think as did our forefathers, and has thereby increased our responsibility to our juniors. and those who seek our guidance.

Never was progress more rapid than in these post-Darwinian days. Steady work in the discovery and classification of genera and species has proceeded all along the line, and with extending influence in the far East. Some idea of what is now taking place in our chosen field may be formed from the fact that, since the adoption of western methods by the Japanese, we have not only to record zoological discoveries of first-rate order, due to the fact that they alone possess the material upon which they are based, but to their lasting credit be it said that they have put us right on fundamentals upon which we have for generations imagined we knew all. To wit, a young Japanese, Hirota by name, alas, now dead! availing himself of the discovery by his teacher of a peculiar condition of the eggmembranes in the native tortoises, was led to argue that since these creatures and birds are not so very distantly related, the like might be forthcoming in them; and turning to the common chick - the bird most ready to hand-he succeeded in proving not only the existence of the condition suspected, but that we in the West, with our boasted methods and resources, by error of orientation, contenting ourselves with the mere examination of parts, instead of the whole object, have gone wrong on an elementary and most important detail.

One immediate effect of the demonstration of the truth o. evolution, now historically established, has been the substitution for the old-fashioned and merely tabular classifications of animate beings, of linear arrangements and phylogenetic trees. To those of the Hæckelian school, fired by an energy of enthusiasm, it appeared easy to locate every known creature to its proper place in the series; but while these persons did good by the stimulating influence of their work, it is needless to say that the hasty construction of such schemes must be fraught with error. So colossal a task is not to be achieved in a lifetime, and it too soon became evident that these fantastic expressions of supposed facts, like all classificatory formulæ, had to give way under the growth of knowledge, until now the time has come when our classifications of animals, which, be it said, are at best but the tentative expression of our ideas, are being based, not on the mere characters of the exterior, or of a single series of parts, but on the sum total of the maximum number of characters observable. Where we once thought we detected relationships, we now know we were often being misled, and the old-time supposition that mere community of structure is necessarily an index of community of origin has gone to the wall.

The past three decades will be ever memorable in the history of biology as that of what may be termed the embryological reaction, prompted by the thought that the clue to the origin of an animal in the remote past lies in the study of its development from the egg, believed to recapitulate the history of its race. Great, however, has been the disappointment in this respect, it having been discovered in many cases that the animate being,

1 Abridged report of the Presidential Address, delivered by Prof. G. B. Howes, F.R.S., before the South-Eastern Union of Scientific Societies, at their Fifth Annual Congress, held in Brighton. 
during its development, is so liable to adaptive change of but passing significance, that it becomes difficult to distinguish between this and the historic record originally believed to be passed through. But, that notwithstanding, upon data of this order many of our recent conceptions of the origin and succession of animal forms have been built up; and it is clear that if, on the basis of such facts, we attempt to deduce those generalised statements we term "laws," the test of our accuracy lies in appeal to the fossiliferous strata, in which we ought to find evidence of their presumed operation in the past. Here I am led to emphasise the importance of the study of palæontology, and, as bearing on the argument deduced from that of development, a striking outcome of recent palæontological investigation has been the unearthing, in the United States of America, of perfectly preserved remains of the Trilobites, the oldest and most primitive of all Crustacean forms. These creatures are now proved to have been possessed of but one pair of antennæ, there being two pairs present in every ordinary later, member of the Crustacean class. It so happens, however, that this is the case for the adults only, and that the presence of but a single pair is characteristic of the larval stage through which all freely developed Crustacea pass, and, from what is now known of the details of the appendages of these Trilubites and the said Crustacean larvæ, there can be no doubt that in this particular class of animals the larva is realistic in its characters of the remote ancestor from which, in past ages, its members have been derived.

Other memorable instances have come to hand in the study of the palæontological record, which have profoundly modified our conceptions of the succession and primary relationships of animal forms. For example, evidence is now accumulating that in the case of birds the remote ancestors were of a more primitive reptilian stock than has been until recently supposed. Again, those structural features in respect to which the living Batrachia simplify the reptilian type are now coming to be recognised as largely due to retrogressive change, and we are beginning to see that both these classes of animals in all probability converge towards an assemblage of palæozoic forms, combining the characters of the two as to-day represented, and that the older naturalists, in classifying the cold-blooded terrestrial vertebrata together, were perhaps not so far out as we have been prone to think. A wonderful chapter has quite lately been added to the history of the horse, by the discovery in South America of an equine animal which possessed the single toe and other features familiar in it. The race to which it belonged has apparently become extinct only in quite recent times, and when we picture to ourselves the course of events to which it points, we conclude that in early Tertiary times the ancestors of the horse tribe, arising in Central America, migrated into the Old World, on one hand, and into South America on the other; and in each, by independent but paralle differentiation, gave rise to an essentially similar definitive form. Survival of this in the Old World alone has resulted in the horses of to-day, those now living in America having been secondarily imported by man.

The case in some respects recalls that of the pig tribe, except that, with this, migration in opposite directions has been accompanied by diversity of modification. Originating in early Tertiary times in Central North America, their ancestors migrated on one hand into the Old World, and by complication of their teeth gave rise to the swine and hogs of later times, while on the other hand, passing into the southern parts of America, they by numerical reduction of their teeth and toes gave rise to the peccaries of to-day.

Taken in conjunction with the now well-recognised fact that certain animals which in life and in all superficial features resemble each other can be proved on examination of more deeply-seated characters to be genetically distinct, this consideration raises the question of the importance of what is known in nature as the phenomenon of "Convergence." We now know of creatures externally almost indistinguishable from slugs which have the internal anatomy of snails and of slugs occurring independently in different parts of the world which exhibit a repetitional similarity of relationship to the snails of their respective areas; and we have long been familiar with a Crustacean -the "King Crab"-living on the opposite shores of the North Pacific, which, in respect to the segmentation of its body and the number and characters of its limbs more especially, conforms to the Scorpionid type. Numerous other instances might be cited, but these are sufficient, and the

NO. I 628 , vOL. 63$]$ question for consideration is, how far such superficial resemblances, in that they have led to the association of forms in which they occur in a common classification, are trustworthy as criteria of affinity. The case for the King Crab and the Scorpion is one of long standing, and there is reason to believe it is still open to doubt. In all groups of Arthropods, to which both creatures belong, we meet with forms in which the familiar free body-rings or "segments" are for the greater part united, and others in which they are free, and there can be no doubt that the degree of union of these, which takes place in definite antero-posterior succession, is a sure index of "highness" and "lowness" in a given series-those in which few segments unite being low, those in which many unite, high. To this process of fusion of body-segments our American confrères apply the expressive term "cephalisation," and, when this test is applied to the two groups to which the animals in question belong, it is found that, in respect to it and certain correlated modifications, they each stand at the summit of their respective series-i.e., that there are, among the "spiders," forms which, at least as regards cephalisation, simplify the Scorpionid type along lines parallel with those in which the so-called Eurypterids of the past, in this and other respects, simplify the King Crab type ; and when, further, it is found that among the fossil Scorpions known there are indications of simplification of exactly the order the facts would lead us to suspect, it follows that King Crab and Scorpion of to-day each hark back to a distinct and independent assemblage of forms. With this, the association together of the culminating types, as in most of our current classifications, becomes dangerous, if not misleading; and we are brought to the realisation of the fact that mere community of adult structure does not necessarily imply community of origin, and that by a parallelism of modification two creatures of diverse ancestry, in adaptation to the conditions of life, may, independently, and by "convergence," assume a similar form.

The approximate resemblance between the crowns of the teeth of the horse and ox is a familiar example, and we have evidence that in this way certain types of teeth represented among the living mammals, by which these are still classified, have been anticipated by totally different groups in past periods of time; and if we are to trust recent research, teeth already modified along lines anticipatory of the carnivorous and herbivorous types of to-day co-existed in an assemblage of supposed cretaceous mammals of South America whose affinities are as yet not fully established.

The extent of the operation of "Convergence" in nature's work is but now becoming recognised, and there is proof to hand that many of our time-honoured classificatory systems are erroneous, by failure of its appreciation in the past. Impressed by this, it behoves us to reflect to what an extent nature's plans, so to speak, have, in the history of organic evolution, as in that of civilisation, repeated themselves, she being apparently intent on a recurrent diversity of differentiation, for some purpose associated with the balance of life we do not understand, as in the fact that when, in Mesozoic times, she had but the reptiles upon which to operate, she produced terrestrial, aquatic and flying forms, just as, in later periods, she has produced them with the mammals, which replaced these in order of time.

Again, with the development of the Darwinian doctrines, there early arose the realisation that, on the principle of descent with modification, the summary appearance of organs having no existence in near allies, either during the development of certain species or on the assumption of the adult state, presented a difficulty which even Darwin himself, ever nore justly critical of his own work than many of his would-be opponents, clearly admitted. The independent appearance of luminous organs and those of electrical discharge in remotely related groups of fishes are ideal cases, at first sight calculated to break the back of the rigid Darwinian. Some thirteen years ago, Dr. Anton Dohrn, of Naples, and the late Prof. Kleinenberg, of Messina, formulated the doctrine of "Substitution of Organs," which provides that under varying conditions of life, and at different periods of development, sets of organs may replace others, to the better fulfilment of the life of the individual or race. To apply this to the case of the organs of electrical discharge in fishes in no way closely related, let it be said that our commonest rays and skates are possessed of such an organ, located in the tail. The peculiar feature of these fishes is the usurpation by their expanded side-fins of the propelling action, which, in ordinary fishes, is performed by the tail. What more 
reasonable, therefore, when we know these rays and skates to have been derived from heavy-tailed shark-like ancestors with small side-fins, than the question how far conversion of the tail into an organ of electrical discharge may not have been the outcome of the taking-on by the side-fins of the swimming function? The answer to this is convincing and complete, for we find among the tropical and more distant allies of these rays, that the tail may become by elongation in one species a delicate trailing whip-lash; by abbreviation in another a mere vestigial stump, or by the addition of spines in yet another a formidable weapon of offence. Clearly, rid of the propelling function, it has become free to modify its ways, and the conversion into an organ of electrical discharge is found to be but one of a series of independent adaptations by "substitution."

Other and more beautiful examples of the working of this law might be cited, such, for example, as that of the provision for "casting" the tail, so well known among living lizards ; but sufficient is before us to show in what manner the advance of knowledge dispels our difficulties, and that the stumbling-block of one generation may become the stepping-stone of the next.

If evolution-defined as the law of descent with modification, and involving the process of progressive advancement and passage with time from the simple to the more complex-is al sufficient to explain the existence and succession of the diverse forms of life, it might well appear that the conditions of modification are more complex and less regular than would have been expected; and we are, therefore, led to inquire in what the determining cause of modification and hereditary tendency may perchance consist. Looking back on the history of biology, three great names stand out above all others as those of the pioneers in its turning-points, Linné, Cuvier and Darwin. Linné taught us how to name and describe the objects in nature; Cuvier impressed upon us the fact that unity of structure underlies the great diversity in superficial form; Darwin, for the first time, furnished the clue to this unity, on the lines to which I have already rcferred, and showed us that vital phenomena are attributable to the working of a fixed set of laws.

It may be said of all living things that, so far as their bodies consist of a mass of living substance, which we term protoplasm, they are structurally identical. In seeking to classify them, be they plants or animals, the sharpest working distinction to be drawn is between those which consist of one structural unit or are unicellular, and those which consist of an aggregate of units or are multicellular-hence our terms Protozoa and Metazoa, Protophyta and Metaphyta, or collectively Monoplastids and Polyplastids, the term "plastid" being sometimes substituted for "cell." While the monoplastids, mostly though by no means all visible only under a lens, consist each of but one cell, one structural unit, of the order of those which in the aggregate compose the body of the polyplastid, there is no fundamental difference recognisable in the manner and extent to which multi. and uni-cellular heings stand related to the universe at large. Both are motile and sensitive; both produce waste, by processes which unchecked lead to decom. position and death; both stand, therefore, in need of recomposition and must be nourished; and both are loyal to the divine command to increase and multiply. It is concerning this reproductive process that the post-Darwinian period has witnessed an altogether unparalleled activity, in the attenut to get at the essence and to unravel the mystery of hereditary influence. The mental giant who has led the way is Prof. Weismann, of the University of Freiburg, in Breisgau. His whole series of doctrines find their focus in three epochmarking addresses, which he delivered in $1881-1883$ before the Association of German Naturalists and his University, entitled "On the Duration of I,ife," "On IIeredity" and "On Life and Death." He took his stand upon the well-known fact that whereas reproduction of the unicellular organism is by a simple process of fission, the individual dividing into two without loss of substance, and becoming at once parent and off. spring-in the multicellular organism the reproductive act in volves only an insignificant portion of the body, and is sooner or later accompanied by the death of that which remains, and a consequent loss of substance. From this he argued that inasmuch as it is conceivable that the fissiparous process may go on indefinitely, the Protozoan of to-day may have arisen by repeated and proionged fissiparous activity from that of long passed ages, and that the organism, never having suffered a loss of substance, may be immortal. Founding, in this way, his doctrine of the "Immortality of the Protozina," he was lecl, by realisation that that portion of the body of the multicellular organism which fulfils the reproductive function passes to its share in the forma. tion of a new individual a living element, to distinguish between it, the "germ-plasma" which never dies, and the rest of the body" or "somatoplasma," which is lost by decomposition and death, and he in this way sought to extend the conception of immortality to the reproductive elements of the higher organisms.

This marvellous generalisation-prettier far than poetrycreated in the early "nineties" a veritable furore; and it furnishes us with material for reflection and inental consideration of an altogether unique order. Su profound, however, was its effect upon contemporary science and thought, that under its influence there arose a horde of eager investigators, intent on its development and the search for the seat of primary hereditary influence. The literature and vexed controversies which have in consequence arisen are now voluminous, and Weismann and his followers, eager to push forward, have pressed theory upon theory, often with contradictory effect. His whole series of observations, however, focus in the afore-named great generalisation, and, as for alleged contradiction, I can only regard it as due to the influence of his friends, who, eager for his advance, and perhaps, in the case of some, for assuciation with his work, forced him to extremes which he would never have contemplated had he been left alone.

As might be supposed, the conception of the inmortality of protoplasm has not passed unchallenged. Maupas, an acute French investigator, has discovered of the familiar "Bell Animalcules," that prolonged fissiparous reproduction is accompanied by progressive diminution in stature, leadin, if un. checked, to senility and decay; and, having determined by observation the number of generations in which this veritable extinction may be brought about, he has succeeded in proving that, by means of a conjugative process, involving a blending of two individuals, its effects are overcome. 'To what this remarkable discovery may ultimately lead we know not, but it so happens that, whether the conception of immortality be right or wrong, it arose in the minds of trained naturalists long before Weismann's time. He himself starts with a quotation from Johannes Miiller, the founder of comparative anatomy, to the effect that "organic bodies are perishable, and that, while life maintains the appearance of immortality, in the constant succession of similar individuals, the individuals themselves pass away." And similarly, R. Owen, in two great lectures on "Parthenogenesis," delivered before the Royal College of Surgeons, in I849, came nearer the mark, with the astounding paragraphs:"Not all the progeny of the primary germ-cell are required for the formation of the body of all animals; certain of the derivative germ-cells may remain unchanged, and become in. cluded in that body which has been composed of their metamor. phosed and diversely combined or confluent brethren. So included, any derivative germ-cell . . . may commence and repeat the same processes of growth and imbibition, and of propagation by spontaneous fission, as those to which itself owed its origin, followed by metamorphoses and combinations of the germ-masses so produced, which concur to the development of another individual, and this may be, or may not be, like that individual in which the secondary germ-cell or germ-mass was included."

And, concerning the conception of immortality of the Protozoa, he also wrote :-

"It is by no means easy to find a name for the relation in which the fissiparous monad stands to the two monads between which it has been equally divided. $A$ parent retains its individuality distinct from its progeny; but the monad has become a part, and indeed the chief part, of the two that have resulted from its spontaneous fission. Both separate moieties are, in an equal degree, the same individual as the whole from which they proceeded; and in an infinitesimal, though conceivable, degree, the actual monarl is the same individual as the first created one, from which it may have proceeded by an uninterrupted succession of spontaneous fissions, and in that degree it may be viewed as one of the oldest known individuals in creation, the individual being never wholly or in part deceased."

Not that this in any way detracts from the merits of Weismann's labours! On the contrary, to him is due the credit of having put the vitally important topic which now concerns us on a scientifically sound and workable basis-an achievement of which he may well be proud.

It being evident that the unicellular and multicellular organisms sland alike responsitble to the universe at large concerning

No. I 628 , voL. 63$]$ 
their functional activities, we are led to inquire in what way the localisation of these in the higher and compound forms may have come about. "Differentiation of labour" is the popular explanation, and one is prone to ask whether the structural or the functional differentiation was first achieved. It has generally been taught in the past that the structural preceded the functional, but we are now coming to doubt this long-cherished conclusion, in evidence of the fact that nature will, with equal facility, effect corresponding differentiation for the fulfilment of the same end in either the whole body of a unicellular organism or a localised part of a multicellular one -in either a single cell or a cellaggregate-as, for example, in the formation of what are known as the ciliated membranellix of the Infusor Stentor, and the socalled corner-cells of the Mollusc Cyclas. Differentiation depends, not on the interaction of cells, but upon the elementary structure and potentialities of protoplasm, or, as Prof. C. O. Whitman, of Chicago, has expressed it, "organism precedes cell-formation."

If this be so, there is raised the question how far the idea, developed during the past two decades, that the animate being is a mere blind automaton, and its actions but complicated functions of a chemico-physical order such as we deduce from the study of the inanimate, is correct, and we are prone to inquire if the structural units of the animal body are, so to speak, bricks set to a mathematical relationship, controlled by laws of pressure, or living units, capable of working to their own ends, and defying mechanical conditions such as apply to the inanimate.

It has long been said of us devotees to the observational branches of science that our methods are inaccurate by lack of qualitative treatment, and the distinction has been drawn bet ween ours, the so-called "inexact," and the mathematical or " exact" sciences. On this basis there are now being pushed forward attempts to apply statistical, experimental and mathematical tests to the study of vital phenomena. All honour to those who are making them, for it is certain there are phases of life capable of mathematical treatment, but the mystery of life can never be thus solved; and, concerning the objection to the observational method, I would remark that if by that we are to understana observation, with confirmation and generalisation, and rejection of the non-confirmable, our non-mathematical procedure is scientific. Huxley has long ago said of mathematics that what you get out of the machine depends entirely upon what you put into it.

Ten years ago, any one asked to define the nature of the primitive organism from which all organic beings are descended, having regard to then known chemical phenomena of life, would most certainly bave argued in favour of a green-plant, or of some organism capable of decomposing $\mathrm{CO}_{2}$ under the action of sun light, and of raising inorganic substances to an organic level, therelsy rendering them fit for animal food. We now know of the existence of lowly organisms capable of decomposing $\mathrm{CO}_{2}$ in the absence of chlorophyll. The ploughing in of the roots of certain leguminous plants, in which our German cousins have been for years ahead of us, is now well known to be associated with the presence of fungi, capable of assimilating the nitrogen of the soil. In the nitrifying bacteria, we are now familiar with organisms by whose aid ammonia becomes the origin of nitrates and nitrites, and there are others which, by a process of denitrification, effect the reduction of these, with liberation of free nitrogen. And startling indeed is the knowledge that there exist in certain seas, and, it may be, near our very doors, bacteria which possess the marvellous poiver of decomposing sulphates, and of living in an atmosphere of sulphuretted hydrogen. The discovery that certain lowly fungi are so sensitive to chemical change in their nutritive media, that the presence of one part in 50,000 of zinc chloride will act as a powerful stimulus, and produce a growth some 700 times its own initial weight, and that one part in $1,600,000$ of silver nitrate is abruptly fatal to it, is simply astounding.

Turning to the animal, we find that whereas in the case of the hot.blooded rabbit the weight of oxygen per hour sufficient for the maintenance of life is as 2.284 , in the case of the cold blooded American turtle it falls to 0.088 . With the animal, as with the plant, so sensitive are the parts of the body to variation in chemical composition of fluids with which they may be brought into contact, that, under conditions of experiment, it has been found that the heart of a frog, of which the beat has been lessened or arrested by treatment with salt-solution or distilled water, may be revived by the accession of one part in 10,000 of calcium carbonate.

No. 1628 , vOL. 63$]$
What all this means, regarding the processes involved in the mystery of life, and in what direction it is leading us, the future can alone sufficiently show. One thing is certain, that since living matter in all its forms is constantly undergoing waste and disintegration by oxidation, life is possible only under a penalty of death, and we are prone to inquire if this is a mere chance circumstance or a necessity to some beneficent end. We know that in the order of evolution the simpler forms of plants and animals have, by combination and advancement, given rise to the more complex, and it is clear that if this process were to go on indefinitely, a time night come at which all the simpler forms would be used un, and life would cease. The breaking up of the complex forms and the dissociation of their elements, however, results in the return to mother earth of the raw material of which they are composed, and thereby renders possible the repetition of the cycle, and from this it follows that the destruction of the individual may have been really a necessity, in order that others might live.

In this consideration we are once more brought into touch with inorganic nature, and it is a remarkable fact that the very chemical elements which enter into the compusition of the simplest protoplasmic structures are precisely those contributing to the formation of the simplest of chemical substances, so far, at any rate, as hydrogen, oxygen, nitrogen, sodium, calcium, magnesium and iron are concerned. My friend and colleague, Sir Norman Lockyer, has recently emphasised this consideration, and, with a boldness worthy his great reputation, has dared to discuss the significance of the facts. The spectroscopic analysis of the hotter stars has revealed to him the truth that their simple chemical constitution is explained by the fact that the final products of dissociation by heat are the earliest chemical forms. From this he deduces the conclusion that with the heavenly bodics, as with the organic world, the simplest forms appeared first, and that the dissociation stages of the former, as of the latter, reveal to us the forms the coming together of which has produced the thing dissociated or broken up. Passing from the hottest to the cooler stars, he argues that, like the various geologic strata, these bring before us a progression of new forms of increasing complexity in an organised sequence, and, developing this pregnant line of thought, he reverts to the uniform simplicity in chemical constitution of the earliest inorganic and the primitive organic forms, and deduces the belief that " the first organic life was an interaction, somehow or other, between the undoubted earliest chemical forms." It is a far cry from the primitive monad to the hottest star, but so convinced is Sir Norman Lockyer of the analogy between the methods of organic and inorganic evolution, that he has used the latter term as the title of his book, which I can strongly recommend to your earnest consideration. We advance by facts, we live by ideas, and if Sir Norman Lockyer's fascinating theory does no more than set the trained mind to work and arouse interest. in the topics with which it deals, it will have served its purpose.

To turn now to the physical properties of living matter. Concerning the eye, it may be said that in the contraction of its retinal pigment by a vital act in definite response to the rays of the spectrum, and in the falling to a focus, within the substance of the crystalline lens, of the inverted image formed by that, it is neither constructed nor behaving in the manner of the inanimate photographer's camera, with which it has been ad nauseam compared! Again, the discovery in recent years that whereas, during life, the gaseous diffusion of respiration does not take place in strict conformity with the laws applying to inanimate membranes, it does so after death, with that of the changes and processes undergone by the food in its passage through the intestinal wall, now proved to be of no mere mechanical order, testify to the conclusion that the moment you bring the conditions and arguments deduced from the study of the inanimate to bear upon what may be expressively termed the animate organic membrane, they either do not apply or are set at defiance.

Many other examples might be cited. We are getting back to a conception of a "vital force," not of the order of the ancients-a "Psyche"-a mysterious controlling influence beyond our ken, but one which we may term a Neo-Vitalism, which teaches us that although organic matter is in its manifes tations chemical and physical and the basis of life is associated with chemical and physical processes, the physics and chemistry are not those of the inanimate as at present understood, and gives us hope of its discovery if we will but persevere.

Finaliy, as to the charge of inexactitude. It is one of the 
blessed aspects of the study of animate nature that there may be the alternative interpretation. Work at a problem long as you will, you will find that when you flatter yourself you have obtained the clue to its significance it will often happen that it is just that which you have missed.

Call it ambiguity if you will; it is primarily due to the structural and functional complexity of living matter, and there lies in it, to my mind, the greatest charm of our science, in that it appeals to the imagination, and therein arouses one of the highest of the intellectual faculties. We work in hope, content to investigate the reason of phenomena, but the nature of things will be ever beyond our grasp.

As contributing to the advancement of knowledge, and to a fuller understanding of the phenomena which underlie the operations of nature, the topics to which I have drawn attention are among the most important in the recent progress of science -the most revolutionary results of patient, persistent inquiry. In their definitive form, the so-called "laws of nature" are but generalised statements of fact, and, so far as we are individually concerned, I would remind you that, since we are but members of the great animal subkingdom, dependent, with the probable millions of species which compose it, upon a common set of conditions in our relations to the universe at large, it is impossible, if we would know and appreciate our position in the world, to present a deaf ear to their teaching. It behoves us not only to ponder them on our own account, but to see to it that, as time progresses, those committed to our charge are so brought up as to be not wholly ignorant of them.

And this brings me to the concluding portion of my address. As members of local committees and scientific societies, we are pledged to the task of what is known as popular education, and its correlate the "popularisation of science." Exactly what this hackneyed expression may be taken to imply I have never yet discovered, and, speaking for myself, I regard it as erroneous. Science cannot be popularised, and any work today worthy the name of scientific must be technical. To popularise science is an impossibility, but to popularise the results of it is quite another thing.

Our task is educational, and we have to encourage a love of those subjects which form the basis of the dictrine of "organic evolution," from which has arisen the greatest revolution in thought and the conduct of life the world has ever seen. How heavy the responsibility we thus incur! How poor the encouragement we, for the most part, receive at the hands of our fellow citizens! To the credit of our nation, be it said, the State is now alive to its responsibility in the matter, and to that of our County Councils, that they are doing their duty towards the higher education and science in particular. But I have grave doubts if the best is being done by private enterprise, which in all matters of progress is a characteristically British method of procedure in the higher walks of life. How many of us, competent to aid in the local management and organisation of museums and scientific institutes, are doing all that we might to keep those in charge of them on the right path. One still finds exhibited the omnium gatherum of scraps, the product of nature overshadowed by the artifice of man. In place of the representative collection of objects of local interest, of specimens and maps which should furnish a key to the physical constitution of the neighbourhood, and which a visitor has a right to expect on entering a strange land, one too often finds the rumble-jumble of odds and ends, with here and there a hidden treasure. There is a so-called "museum" not many miles from this place, in which payment is extracted from the visitor to behold, as a conspicuous exhibit amidst a collection of oddments, a milk tin recovered from the Fram, which Nansen would himself probably disown! Local control and organisation should render this sort of thing impossible, despite its being due to "private enterprise," and you must please pardon me when I draw attention to the fact that we in the south are behind our northern brethren in respect to local organisation for science and the higher education. I can conceive no better outcome of this meeting than that we should at once resolve, by connected action, to put this right.

On appeal to a frivolous public, we are told there is nothing to come of it, that work of the kind to which we aspire is not remunerative, and that the cultivation of scientific tastes is to be avoided, as narrowing in effect and tending to dwarf the religious instinct, and foster doubt. To this I would reply (I) that most of our boasted advantages in civilisation have been due to the outcome and the application of science

NO. I 628 , vOL. 63$]$ to daily life and domestic use ; (2) that there is no better tonic for the human mind than that afforded by perusal of the works of nature; (3) that the existence of matter, "motion, and law-abiding operation in nature, are greater miracles than were ever recounted by the mythologies"; and (4) that science, with love, now rules the world.

To counteract the tendency of our time, it is for us to see to it that the selection and arrangement of the exhibits in our museum collections shall furnish the visitor with a series of local object lessons, both attractive and instructive, and so ordained as to create in the mind of the mere passer-by-as can readily be done by the excellent system of descriptive labelling now coming into vogue-a desire to know more of his immediate surroundings, and, through them, of his position and relationships as a dweller in the neighbourhood and a factor in the universe at large.

The aim and object of not a few of our local scientific societies would seem to be publication rather than this, and against the tendency I would urge every influence I can command. If confined to mere local records of fact, Proceedings or other publications, maintained in moderation, are well and good, but, with larger and central institutions given to the meeting of persons from various localities for comparison of local forms and discussion of broad principles, the local society, in striving after this, is exceeding the bounds of reasonable distribution of labour.

Once again let me remark that we can have no higher object in view than the capture of youth. Huxley has wisely said :-

"The great end of life is not knowledge, but action. A small percentage of the population is born with special aptitude of some sort or another; and the most important object of all educational schemes is to catch these exceptional people, and turn them to account for the good of society ... and to put them into the position in which they can do the work for which they are specially fitted."

And he added :-

"That if the nation could purchase a potential Watt, a Davy, or Faraday, at the cost of $100,000 /$. down, he would be cheap at the money."

To me nothing would be more gratifying than that there might result from this meeting an agreement upon a line of action which might track a genius and place him on the ladder he was born to ascend, to the permanent glory of his race and benefit of the world at large.

In these days, when bombast and self-assertiveness are apt to be mistaken for executive power, we want all the origin. ality we can secure. Learning is but our knowledge of the experience of others, knowledge our very own! Higher ambition than that of adding to the sum of knowledge no man can have; wealth, influence, position, all fade before it, but we must die for it if our work is to live after us.

\section{UNIVERSITY ANI) EDUCATIONAL INTELLIGENCE.}

A COURSE of lectures and demonstrations in practical hygiene for teachers will be held partly at Bedford College and partly at the Sanitary Institute, on Saturday mornings during the three terms of the present year.

WE learn from Science that Mr. John D. Rockefeller has made a further gift of $I, 500,000$ dollars to the University of Chicago. Of this sum, $1,000,000$ dollars is to be used as an endowment fund. 'The balance of the gift is to be used for general needs. Mr. Rockefeiler suggests that 100,000 dollars be used for the construction of a university press building. Mr. Leon Mandel has given 25,000 dollars to the University, in addition to his previous gifts.

ONE of the most important developments recorded in the recent report of the Somerset County Education Committee is the presentation, by Lord Portman, of an experimental farm, five miles from 'Taunton. The farm consists of 142 acres, of which 80 are pasture. Lord Portman has made considerable alterations and additions to the farm buildings in order to bring them up to date and to adapt them to the requirements of the County Committee. The primary object of the farm will be experiments on the profitable feeding of farm animals of various 